\title{
Gravid uterus in an incisional hernia with uterine scar dehiscence: a case report
}

\author{
Anjali V. Kanhere ${ }^{1 *}$, Gurpreet K Nandmer ${ }^{1}$, Ashok Mhaske ${ }^{3}$ \\ ${ }^{1}$ Department of Obstetrics and Gynecology, ${ }^{2}$ Department of Surgery, PCMS \& RC, Bhopal, Madhya Pradesh, India
}

Received: 18 August 2013

Accepted: 3 September 2013

\section{*Correspondence:}

Dr. Anjali V. Kanhere,

E-mail: kanhereanju@yahoo.com

(C) 2013 Kanhere A et al. This is an open-access article distributed under the terms of the Creative Commons Attribution Non-Commercial License, which permits unrestricted non-commercial use, distribution, and reproduction in any medium, provided the original work is properly cited.

\begin{abstract}
Full term pregnancy in an incisional hernia of the anterior abdominal wall is rare and a serious condition. Initially the hernia is reducible, but as pregnancy advances, it may be complicated by skin ulcerations, incarceration and subsequent strangulation within the hernia sac. Potentially grave obstetric complications such as preterm labour, accidental hemorrhage, intrauterine growth restriction, intrauterine fetal death, scar dehiscence and rupture of the lower uterine scar can occur. We report a case of full term pregnancy in an incisional hernia with uterine scar dehiscence, its clinical course, management and review of literature.
\end{abstract}

Keywords: Pregnancy, Incisional hernia, Caesarean section, Uterus, Scar dehiscence, Skin ulceration

\section{INTRODUCTION}

Incisional hernia of the anterior abdominal wall is uncommon in pregnancy. Full term pregnancy in an incisional hernia of the anterior abdominal wall is rarer. ${ }^{1,2}$

Initially these hernias are reducible but as pregnancy advances, they can present with complications such as incarceration, strangulation, skin ulceration, preterm labour, intrauterine growth restriction, intrauterine fetal death and rupture of lower uterine segment. ${ }^{1-5}$

We report a case of full term pregnancy in an incisional hernia with uterine scar dehiscence, its clinical presentation, management and review of literature.

\section{CASE REPORT}

A 30 year old third gravida, para 2 with one live issue (G3P2001) presented to the outpatient department. She was referred from peripheral district hospital for management.
She presented to the antenatal OPD as a case of 34 weeks pregnancy with previous 2 LSCS with incisional hernia.

On presentation, she had a history of eight and half month amenorrhea and complained of skin ulceration on anterior abdominal wall for 3 months. She also had discomfort and a dragging sensation in abdomen.

Her obstetric history revealed a term LSCS three years back for CPD and fetal distress. The baby died after 24 hours neonatal care admission. The second pregnancy was a term LSCS for previous cesarean section, $1 \frac{1}{2}$ years back. She had a prolonged postoperative period with wound infection, which was managed by antibiotics and daily wound care.

Physical examination revealed a short statured woman belonging to a low socio-economic group, with stable vitals.

Abdominal examination revealed a midline vertical infraumbilical scar with a large hernia sac containing a 
34-week size pregnancy, which was dropping down up to the mid thighs (Figure 1).

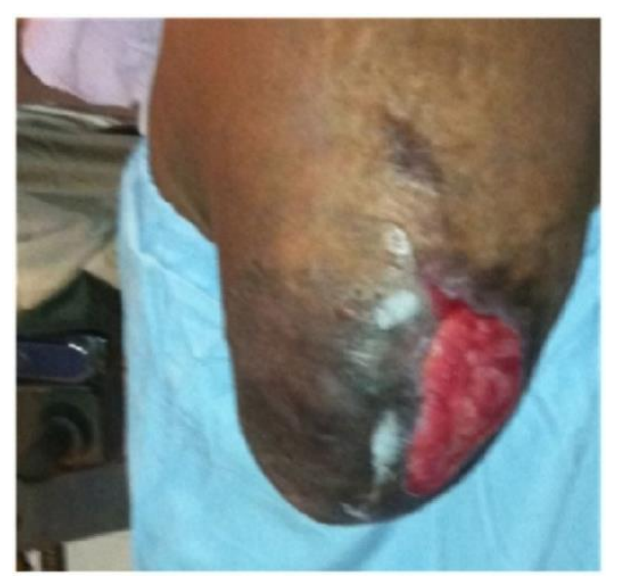

Figure 1: Anterior view gravid uterus in incisional hernia.

Skin ulceration was present. The ulcer was paramedian on the left side of abdominal wall, extending in umbilical, hypo gastric region, irregular in shape $12 \mathrm{~cm}$ x10 cm with granulation tissue (Figure 2).

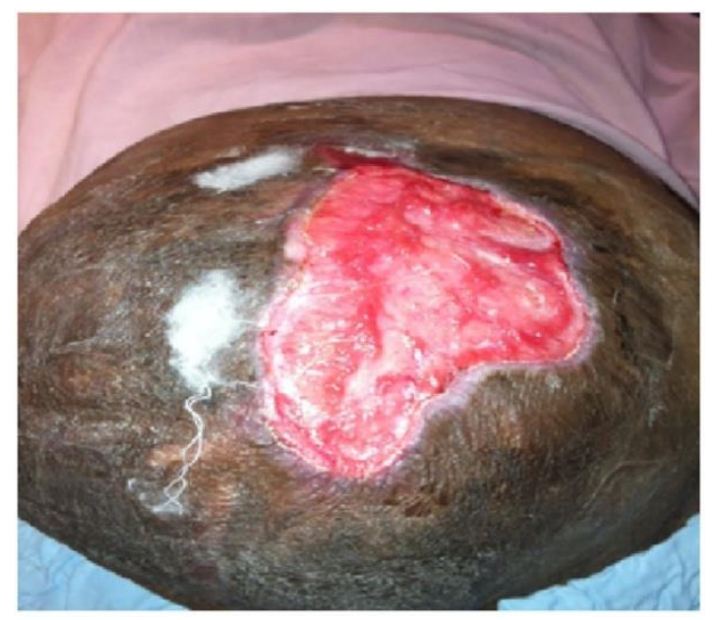

Figure 2: Ulceration over abdominal skin.

Hemogram and urine examination was normal. Obstetric ultrasound revealed a 33-weeks live single fetus in longitudinal lie with the anterior implantation of the placenta, placental maturity grade I with no obvious congenital malformations with oligohydramnios (reduced amniotic fluid index $2 \mathrm{~cm}$ ). It also showed uterus herniated in the incisional hernia of the anterior abdominal wall leading to limitation of study.

An elective LSCS with herniorraphy with tubal ligation was planned at 38 weeks. Corticosteroid prophylaxis was given in view of the gestational age. Daily dressing of ulcer was done. One week after the admission, patient was taken up for emergency LSCS with tubal ligation as she complained of pain in abdomen.
The abdomen was opened by paramedian vertical incision. Hernia sac was incised; uterus was lying in the sac. Scar dehiscence of about $2 \mathrm{~cm}$ was present which was covered by the clot (Figure 3).

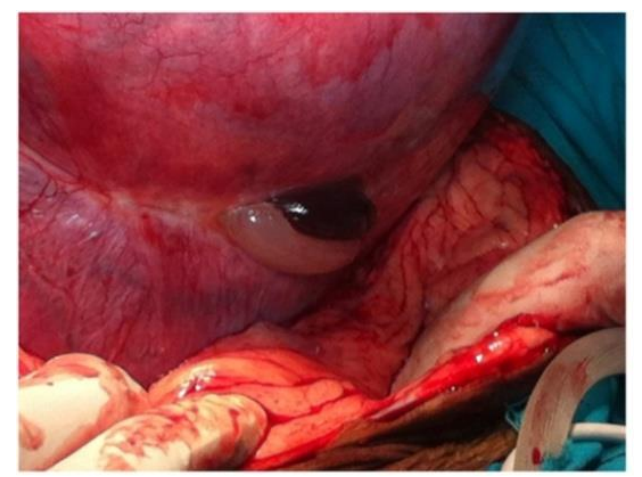

Figure 2 Uterine scar dehiscence covered with clot and membranes.

She delivered a male baby of $2.7 \mathrm{~kg}$ with Apgar score of 7 and 9 at 1 and 5 minutes respectively. LSCS with bilateral tubal ligation was performed Anatomical repair of the sheath was done with 1-0 polypropylene running locking suture after excision of the hernia sac. Redundant skin and subcutaneous tissue was excised and skin was sutured (Figure 4).

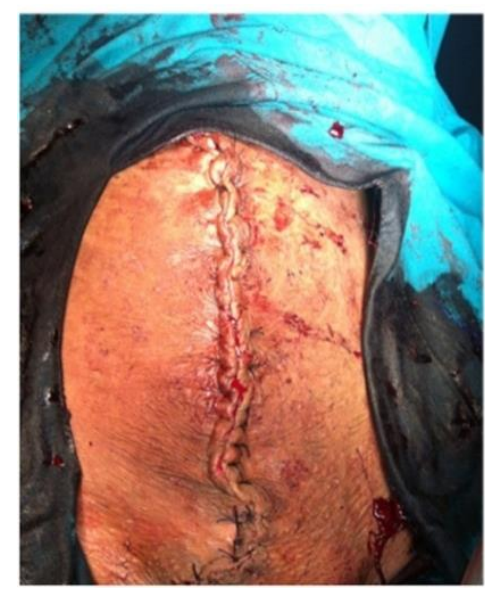

Figure 43: Abdominal wall repair.

Her postoperative period was uneventful. Stitches were removed on the $10^{\text {th }}$ postoperative day. Patient and baby were discharged on $12^{\text {th }}$ postoperative day.

\section{DISCUSSION}

The herniation of gravid uterus has been reported sporadically as anterior abdominal wall incisional hernia and umbilical hernia of pregnancy. ${ }^{6,7}$ A literature search revealed only 15 reported cases of anterior abdominal wall hernias complicated by pregnancy. $2,3,5,8,9$

Onsets of herniation have been reported from 4 to 8 months of gestational age. ${ }^{2,4}$ 
Full term pregnancy in an anterior abdominal wall incisional hernia is a real obstetric problem. It may cause ulceration and excoriation on the anterior abdominal wall and bleeding from ulcerated area leading to shock incarceration, strangulation, and burst abdomen. $3,8,10$

Obstetric potential complications like pre-term labor, intra-abdominal growth restriction, accidental hemorrhage, IUFD, rupture of lower uterine segments, dysfunctional labor and PPH can happen, this is a grave condition for the mother and the fetus.

Herniation of gravid uterus in incisional hernia is associated with cesarean section, accounts for $3.1 \%$ of all cesarean sections. ${ }^{2}$ With rise in rate of Cesarean section world over; there is an increased possibility of developing this complication. ${ }^{4}$ Number of previous Cesarean sections, healing with secondary intention, midline vertical incision postoperative fever, wound infection, wound dehiscence influences the incidence of incisional hernia. $^{1-5}$

As in our case there is a history of postoperative fever and wound infection in prior surgery.

The diagnosis of gravid uterus in incisional hernia is made by presence of an unusual bulge of the abdomen with stretched thin skin, the easily palpable uterus and fetal parts. Imaging study with ultrasound assist in diagnosis. ${ }^{2}$ This helps in diagnosing pregnancy complications like IUGR, Oligohydramnios but has limitations in analyzing scar integrity, as it happened in our case.

Conservative management till term, early hospitalization and elective cesarean section with hernia repair mesh or suture repair is recommended. ${ }^{3,5}$ In our case the patient was taken for emergency cesarean section because of pain. The uterine scar dehiscence was not diagnosed prior to surgery.

\section{CONCLUSION}

Management of patient with gravid uterus in incisional hernia needs to be individualized depending on the patient's everyday complaints and the gestational age. Diagnosis is based on the history, examination and ultrasound examination. Conservative management till term is recommended. Awareness of all complications and unusual presentation of complications and management can help to achieve successful pregnancy outcome.

\section{Funding: None \\ Conflict of interest: None declared \\ Ethical approval: Not required}

\section{REFERENCES}

1. Sahu L, Bupathy A. Evisceration of pregnant uterus through the incisional hernia site. J Obstet Gynaecol Res 2006;32:338-40.

2. Saha PK, Rohilla M, Dahiwal LK, Gupta I. Herniation of Gravid Uterus: Report of 2 Cases and Review Literature. Medscape General Medicine 2006;8:14.

3. Malhotra M, Sharma JB, Wadhwa L, Arora R. Successful pregnancy outcome of cesarean section in a case of gravid uterus growing in an incisional hernia of the anterior abdominal wall. Indian $\mathrm{J}$ Med Sci 2003; 57:501-3.

4. Modi JN., Bharadwaj, M., Kalra, R., \& Mhaske AN. Incarcerated Gravid Uterus in an Incisional Hernia. International Journal of User-Driven Healthcare 2012;2: 5-13.

5. Banerjee N, Deka D, Sinha A, Prasrad R, Takkar D. Gravid uterus in an incisional hernia. J ObstetGynaecol Res 2001;27:77-9.

6. Dare FO, Makinde OO, Lawal OO. Gravid uterus in abdominal wall hernia of a Nigerian woman. Int $\mathbf{J}$ Obstet Gynecol 1990;32:377-79.

7. Thomson SW. Two unusual complications of umbilical hernia in pregnancy. Br Med $\mathrm{J}$ 1962;2:1586.

8. Nagpal M, Kaur S. Herniated pregnant uterus with bleeding from previous abdominal scar. J Obstet Gynaecol India 2003;53:283.

9. Deka D, Banerjee N, Takkar D. Incarcerated pregnant uterus in an incisional hernia. International Journal of Gynecology\& Obstetrics 2000;3:377-79.

10. Ray KK, Aggarwal S, Banerjee K, Karan S, Charu C. Gravid uterus in an incisional hernia leading to burst abdomen. Internet J Gynecol Obstet 2005;5:2.

11. Palazzo F, Ragazzi S, Ferrara D, Piazza D. Herniated gravid uterus through an incisional hernia treated with the component separation technique. Hernia. 2010; 14:101-4.

DOI: $10.5455 / 2320-1770 . i j r \operatorname{cog} 20131236$

Cite this article as: Kanhere AV, Nandmer GK, Mhaske A. Gravid uterus in an incisional hernia with uterine scar dehiscence: a case report. Int J Reprod Contracept Obstet Gynecol 2013;2:674-6. 